\title{
Luminal leptin inhibits L-glutamine transport in rat small intestine: involvement of ASCT2 and $\mathrm{B}^{0} \mathrm{AT} 1$
}

\author{
Robert Ducroc, ${ }^{1}$ Yassine Sakar, ${ }^{1}$ Carmen Fanjul, ${ }^{2}$ Ana Barber, ${ }^{2}$ André Bado, ${ }^{1}$ and Maria Pilar Lostao ${ }^{2}$ \\ ${ }^{1}$ Institut National de la Santé et de la Recherche Médicale, U773, CRB3 Faculté de Médecine Xavier Bichat, Paris, France; \\ ${ }^{2}$ Department of Nutrition, Food Science, Physiology and Toxicology, University of Navarra, Pamplona, Spain
}

Submitted 9 February 2010; accepted in final form 5 May 2010

Ducroc R, Sakar Y, Fanjul C, Barber A, Bado A, Lostao MP. Luminal leptin inhibits L-glutamine transport in rat small intestine: involvement of ASCT2 and $\mathrm{B}^{0} \mathrm{AT} 1$. Am J Physiol Gastrointest Liver Physiol 299: G179-G185, 2010. First published May 6, 2010; doi:10.1152/ajpgi.00048.2010.—L-glutamine is the primary metabolic fuel for enterocytes. Glutamine from the diet is transported into the absorptive cells by two sodium-dependent neutral amino acid transporters present at the apical membrane: ASCT2/SLC1A5 and $\mathrm{B}^{\mathrm{O}} \mathrm{AT} 1 /$ SLC6A19. We have demonstrated that leptin is secreted into the stomach lumen after a meal and modulates the transport of sugars after binding to its receptors located at the brush border of the enterocytes. The present study was designed to address the effect of luminal leptin on $\mathrm{Na}^{+}$-dependent glutamine (Gln) transport in rat intestine and identify the transporters involved. We found that $0.2 \mathrm{nM}$ leptin inhibited uptake of Gln and phenylalanine (Phe) (substrate of $\left.\mathrm{B}^{\mathrm{O}} \mathrm{AT} 1\right)$ using everted intestinal rings. In Ussing chambers, $10 \mathrm{mM}$ Gln absorption followed as $\mathrm{Na}^{+}$-induced short-circuit current was inhibited by leptin in a dose-dependent manner (maximum inhibition at $10 \mathrm{nM} ; I_{\mathrm{C} 50}=\sim 0.1 \mathrm{nM}$ ). Phe absorption was also decreased by leptin. Western blot analysis after 3-min incubation of the intestinal loops with $10 \mathrm{mM}$ Gln, showed marked increase of ASCT2 and $\mathrm{B}^{\mathrm{O}} \mathrm{AT} 1$ protein in the brush-border membrane that was reduced by rapid preincubation of the intestinal lumen with $1 \mathrm{nM}$ leptin. Similarly, the increase in ASCT 2 and $\mathrm{B}^{\mathrm{O}} \mathrm{AT} 1$ gene expression induced by 60 -min incubation of the intestine with $10 \mathrm{mM}$ Gln was strongly reduced after a short preincubation period with leptin. Altogether these data demonstrate that, in rat, leptin controls the active Gln entry through reduction of both $\mathrm{B}^{\mathrm{O}} \mathrm{AT} 1$ and ASCT2 proteins traffic to the apical plasma membrane and modulation of their gene expression.

Ussing chamber; intestinal rings; leptin receptor; phenylalanine; qPCR

GLUTAMINE (Gln) is the most abundant amino acid in the plasma. It is absorbed by the intestine, making this organ a key player in the whole body Gln homeostasis. As Gln is a precursor of the nucleosides and glucose synthesis and is involved in the acid-base balance in the kidney, it is crucial for the interorgan nitrogen flux. Gln is also the most important energy source for the enterocytes, lymphocytes, and fibroblasts and is necessary for the growth and viability of cells maintained in culture (5). Gln from the diet is transported into the enterocyte by two sodium-dependent neutral amino acid transporters present in the apical membrane: ASCT2 (System ASC) and $\mathrm{B}^{0} \mathrm{AT} 1$ (System B) (6). ASCT2/SLC1A5 shows high affinity for alanine (Ala), serine, cysteine, threonine, and Gln $\left(K_{0.5}=\sim 20 \mu \mathrm{M}\right)$, whereas $\mathrm{B}^{0} \mathrm{AT} 1 /$ SLC6A19 is a low-affinity transporter $\left(K_{0.5}\right.$ ranging from 1.4 to $\left.4 \mathrm{mM}\right)$ with preference for

Address for reprint requests and other correspondence: R. Ducroc, INSERM, U773, CRB3, Digestive Physiology and Neuroendocrinology, 16 Rue Henri Huchard, 75890 Paris, Cedex 18, France (e-mail: robert.ducroc@inserm.fr). large neutral amino acids, including those with bulky lateral chain as phenylalanine (Phe), a specific substrate for this transporter (6). In the cell, most of the Gln is metabolized to cover its energetic requirements, and the rest is transported to the blood by the basolateral sodium-independent exchanger LAT-2/4F2hc, SLC7A8/SLC3A2 (system L) (6).

Leptin was initially described as an adipostatic signal controlling food intake and energy expenditure (32). Today, it is well known that leptin is a multifunctional hormone that is also involved in immune and neuroendocrine functions and nutrient absorption (22). This action is consistent with the production of leptin by many other tissues $(1,15,23)$, as well as the expression of its receptors in peripheral tissues $(14,22)$. Indeed, we have demonstrated that leptin receptor is expressed in both the apical and basolateral membrane of intestinal absorptive cells (3). Other authors also showed that leptin is secreted into the gastric lumen after a meal by pepsinogen-containing secretory granules of chief cells (11), which also contain the leptin-soluble receptor, indicating that this leptin receptor isoform is also released into the gastric lumen (12). Bound to this receptor, leptin remains stable in the gastric juice, despite the severe conditions of $\mathrm{pH}$ and proteolytic activity in the gastric lumen, and is able to reach the intestinal lumen (17). Accordingly, we have demonstrated that leptin present in the intestinal lumen inhibits sugar absorption in vivo by regulating the $\mathrm{Na}^{+}$/glucose cotransporter SGLT1 (19). A similar effect was previously reported in vitro $(2,16,18,21)$ with implication of both PKC and PKA activation $(4,16)$. Interestingly, luminal leptin enhances the intestinal transport of dipeptides by the $\mathrm{H}+/$ peptide transporter PEPT1 and CD147/medium-chain triglyceride (MCT)-1 mediated uptake of butyrate in mice and Caco- 2 cells $(9,10)$, as well as fructose transport by the facilitative glucose transporter GLUT5 in rat intestine in vivo (25). Given that leptin seems to regulate different nutrient transporters, one could anticipate that it may also modulate amino acid transporters in the intestine. However, there are not data in this respect yet. Considering the importance of Gln for the whole organism and in the intestine itself, the aim of the present study was to investigate the effect of luminal leptin on Gln transport and the target transporters of the hormone. We found that both ASCT2 and $\mathrm{B}^{0} \mathrm{AT} 1$ are involved in $\mathrm{Na}^{+}$dependent uptake of glutamine in rat intestine and regulated by apical leptin. The present results give new insights into the role of leptin as a major gastrointestinal hormone regulating intake of rich energy molecules.

\section{MATERIALS AND METHODS}

Animals. Male Wistar rats weighing 220-260 g were obtained from Charles River Laboratories, L'Arbresle, France and the Applied Pharmacology Research Center (CIFA) of the University of Navarra, 
Pamplona, Spain. They were caged under standard laboratory conditions with tap water and regular food provided ad libitum, in a 12-h:12-h light/dark cycle at a temperature of $21-23^{\circ} \mathrm{C}$ and fasted for 16-18 h, with free access to water, before the experiments. The animals were treated in accordance with the European Community Guidelines concerning the care and use of laboratory animals. The animal studies were performed under license from the veterinary department of Paris, France (to A. Bado and R. Ducroc, authorization no. 75-955 of September 2, 2004, and no. 75-174 of October 9, 2003, respectively; agreement no. B75-18-02; decision no. 05/12 established on July 12, 2005 by Prefecture of Police de Paris, France). The experimental protocol was approved by the Animal Research Ethic Committee of the University of Navarra, with the no. 064-06.

Everted intestinal ring uptake assays. Rats were anesthetized by intraperitoneal injection of a mixture (4:1) of ketamine chlorohydrate (Ketolar; Merial S.A., Barcelona, Spain) and medetomidine chlorohydrate (Domtor; Pfizer Orion, Espoo, Finland), at a dose of $0.25 \mathrm{ml}$ per $100 \mathrm{~g}$ body wt. Uptake of Gln or Phe by everted jejunal rings was determined as previously described (21). Briefly, rats were anesthetized, and a segment $(20-25 \mathrm{~cm})$ of jejunum was quickly excised, rinsed with ice cold saline solution $(\mathrm{NaCl} 0.9 \%)$, everted, and cut into $\sim 30$-mg pieces. Groups of six rings were incubated for $15 \mathrm{~min}$ at $37^{\circ} \mathrm{C}$ under continuous shaking and gassed with $\mathrm{O}_{2}$, in Krebs-RingerTris containing $0.5 \mathrm{mM}$ Gln or $50 \mu \mathrm{M}$ Gln (Sigma-Aldrich, St. Louis, $\mathrm{MO})$ and $0.064 \mu \mathrm{Ci} / \mathrm{ml} \mathrm{L}-\left[{ }^{14} \mathrm{C}(\mathrm{U})\right]$-glutamine $(218 \mathrm{mCi} / \mathrm{mmol}$; American Radiolabeled Chemicals, St. Louis, MO) or $0.5 \mathrm{mM}$ Phe (Merck, Darmstadt, Germany) and $0.064 \mu \mathrm{Ci} / \mathrm{ml} \mathrm{L-}\left[{ }^{14} \mathrm{C}(\mathrm{U})\right]$-phenylalanine $(370$ $\mathrm{mCi} / \mathrm{mmol}$; American Radiolabeled Chemicals), in the absence (control) and in the presence of $0.2 \mathrm{nM}$ recombinant rat leptin (Peprotech EC, London, UK). After the incubation period, rings were washed in ice-cold saline solution and radioactivity incorporated into the tissue was determined by liquid scintillation counting. Results are expressed as picomoles amino acid per gram wet weight per minute ( $\mathrm{pmol} / \mathrm{g}$ per min).

Tissue preparation and short-circuit measurement. Animals were euthanized by intraperitoneal pentobarbital overdose, and the proximal intestine was dissected out and rinsed in cold saline solution. The mesenteric border was carefully stripped off using forceps and the small intestine opened along this border and rinsed in Krebs-Ringer bicarbonate solution (KRB). Four adjacent proximal samples were mounted in modified Ussing chambers (Physiologic Instruments, San Diego, CA). Exposed area was $0.50 \mathrm{~cm}^{2}$. The tissue samples were bathed with $4 \mathrm{ml}$ of carbogen-gassed KRB solution on each side. Serosal KRB solution had the following composition (in $\mathrm{mM}$ ): 115.4 $\mathrm{NaCl}, 5 \mathrm{KCl}, 1.2 \mathrm{MgCl}_{2}, 0.6 \mathrm{NaH}_{2} \mathrm{PO}_{4} 25 \mathrm{NaHCO}_{3}, 1.2 \mathrm{CaCl}_{2}$, and 10 glucose. In mucosal KRB solution, glucose was replaced by mannitol. Each reservoir was gassed with $95 \% \quad \mathrm{O}_{2}-5 \% \quad \mathrm{CO}_{2}$ and kept at constant temperature of $37^{\circ} \mathrm{C}$ ( $\mathrm{pH}$ at 7.35$)$.

Electrogenic ion transport was monitored continuously as shortcircuit current $\left(I_{\mathrm{sc}}\right)$ by using an automated voltage clamp apparatus (DVC 1000; WPI, Aston, England) linked through a MacLab 8 to a MacIntosh computer. Results were expressed as the intensity of the $I_{\mathrm{sc}}$ $\left(\mu \mathrm{A} / \mathrm{cm}^{2}\right)$ or as the difference $\left(\Delta I_{\mathrm{sc}}\right)$ between the peak $I_{\mathrm{sc}}$ after amino acid challenge and the basal $I_{\mathrm{sc}}$ measured just before the addition of the amino acid. Leptin was added in either the mucosal or the serosal bath 2-10 min before Gln challenge in the mucosal bath.

We found that there were no difference either in the quantitative sodium-dependent Gln transport or in the effect of leptin between middle jejunum and middle ileum, so the rest of studies were performed using middle small intestine (jejunum-ileum).

Western blot analysis. Fasted rats were anesthetized by intraperitoneal administration of pentobarbital and laparotomized. Three small intestinal loops (7-cm length) per rat were prepared as previously described (16). They were filled with $3 \mathrm{ml}$ of KRB-mannitol without (2 loops) or with $1 \mathrm{nM}$ leptin (1 loop) using a syringe equipped with a 30-4/10 hypodermic needle (Acierinox; Vincent, Paris, France). After 3-min in vivo incubation, the loop containing leptin and one loop without leptin were filled with $\sim 1 \mathrm{ml}$ of a $10 \mathrm{mM}$ Gln solution and again incubated for $3 \mathrm{~min}$. This protocol was performed in four different rats where the loops were treated in a randomized way. In some rats, one loop was injected with leptin but without Gln. After death, loops were removed and opened along the mesenteric border, and the mucosa was scrapped off on ice with a glass blade. Brushborder membrane vesicles (BBMV) were prepared from mucosa scrapings as previously described (16). Protein concentration was quantified using the BCA protein assay Kit (Pierce, Rockford, IL). Solubilized proteins were resolved by electrophoresis on $12.5 \%$ SDSPAGE gels. The resolved proteins were transferred onto nitrocellulose membranes and subjected to immunoblot analysis with a rabbit antiASCT2 polyclonal antibody (AB 1352; Chemicon Millipore, Temecula, $\mathrm{CA}$ ) diluted 1:7,500, rabbit anti-B ${ }^{0} \mathrm{AT} 1$ at 1:500 (generous gift from François Verrey), or with mouse monoclonal $\beta$-actin antibody (sc-81178; Santa Cruz Biotechnology, Santa Cruz, CA). The intensity of the immunoreactive bands detected by enhanced chemiluminescence (Pierce) was quantified using NIH Image (Scion, Frederick, MD). $\beta$-Actin was used as loading control. The results were expressed in relation to control, and the value of control was arbitrarily set to 1 .

$q R T-P C R$ analysis. Real-time PCR was used to examine the effect of leptin on Gln-induced ASCT2 and $\mathrm{B}^{\mathrm{O}} \mathrm{AT} 1$ gene expression. Rats were anesthetized and laparotomized. Three small intestinal loops of $\sim 8 \mathrm{~cm}$ starting $15 \mathrm{~cm}$ from the cecum were prepared and filled with $1 \mathrm{nM}$ leptin or saline. After 3-min in vivo incubation, loops were filled with $10 \mathrm{mM}$ Gln for $60 \mathrm{~min}$. After this time, rats were killed, loops were dissected and rinsed in saline, and mucosa was scrapped off on ice. Total RNA was extracted from the mucosa samples with the Trizol reagent (Qiagen, Valencia, CA). The first-strand cDNA was synthesized by reverse transcription from $5 \mu \mathrm{g}$ of total RNA with SuperScript II reverse transcriptase (Invitrogen, Cergy-Pontoise, France). Quantification of cDNA was performed with a Light Cycler System (Roche Diagnostics, Meylan, France) according to the manufacturer's instructions. Primers were as follows: rASCT2, f5' - CCACATGCGAAAAGGAATCT-3' and r5'-CTCAAGAGCCCAATTTCCAA-3'; rB ${ }^{\circ}$ AT1, f5' ${ }^{\prime}$ TTACCAAGTCAGGGGGTGAG-3' and r5'-GATGAGGGCTTCATGACGAT-3'; r18S, f5'-CCCTGGCCTTTGTACACACC-3' and r5'- GATCCGAGGGCGCTCACTA-3'. They were designed with oligo 4 software and synthesized by Eurogentec (Southampton, UK). The comparative $\Delta \Delta \mathrm{CT}$-method was used for relative mRNA quantification of target genes, normalized to protein $18 \mathrm{~S}$ and a relevant control equal to $2-\Delta \Delta \mathrm{CT}$.

Chemicals. Recombinant murine leptin was purchased from PreProtech EC (London, UK). All other chemical reagents were purchased from Sigma. Leptin antagonist L39A/D40A (kind gift of Prof. Arieh Gertler) was diluted in saline.

Statistical analysis. All results were expressed as means \pm SE. Student's $t$-test or one-way ANOVA with Tukey-Kramer multiple comparison post test when appropriate were performed using GraphPad Prism version 4.0 for Windows (GraphPad Software, San Diego, CA) or SPSS. v.15. The level of significance was set at $P<0.05$.

\section{RESULTS}

Leptin inhibits glutamine uptake in everted rings. The effect of leptin on Gln uptake was first studied on preparations of everted intestinal rings after 15-min incubation. As shown in Fig. 1A, uptake of $0.5 \mathrm{mM}$ Gln was significantly reduced $(\sim 35 \%)$ by 0.2 leptin. The hormone also significantly reduced, by $\sim 25 \%$, uptake of $50 \mu \mathrm{M}$ Gln, a concentration close to the $K_{0.5}$ for ASCT2 (6) (Fig. $1 B$ ). To evaluate the contribution of $\mathrm{B}^{0} \mathrm{AT} 1$ on Gln absorption at both concentrations, we examined the effect of $25 \mathrm{mM}$ Phe (specific substrate of $\mathrm{B}^{0} \mathrm{AT} 1$ ) on Gln uptake. As depicted in Fig. 1A, Phe reduced $0.5 \mathrm{mM}$ Gln uptake by $\sim 65 \%$, indicating a higher contribution of $\mathrm{B}^{0} \mathrm{AT} 1$ on Gln uptake compared with ASCT2. However, uptake of $50 \mu \mathrm{M}$ was not inhibited by Phe (Fig. $1 B$ ), demonstrating that at this 
A glutamine uptake $(0.5 \mathrm{mM})$

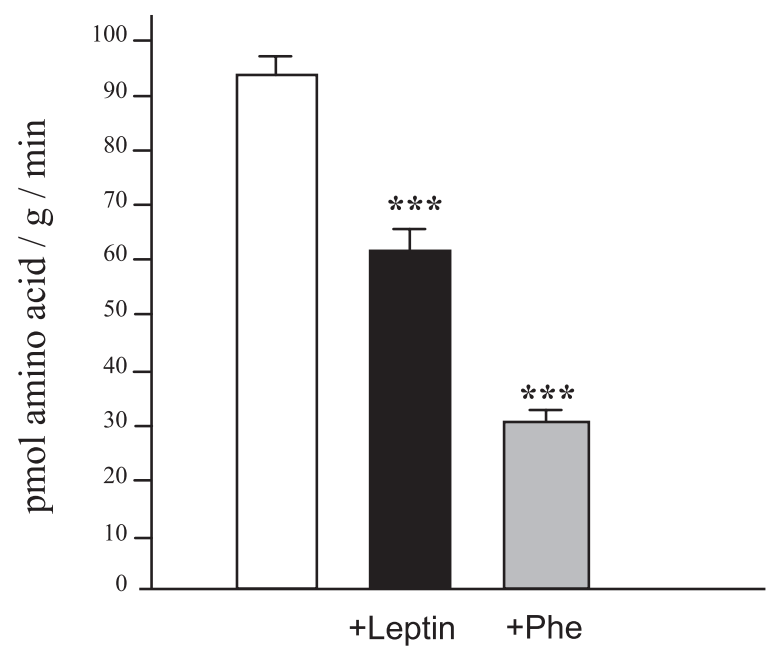

B glutamine uptake $(50 \mu \mathrm{M})$

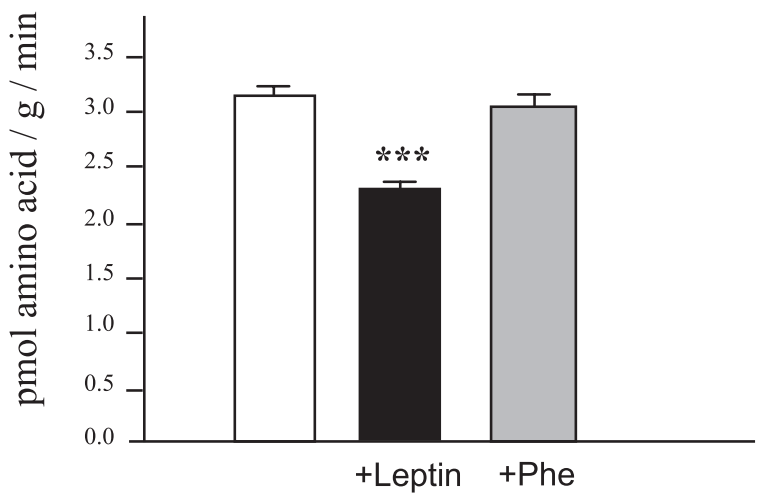

C phenylalanine uptake $(0.5 \mathrm{mM})$

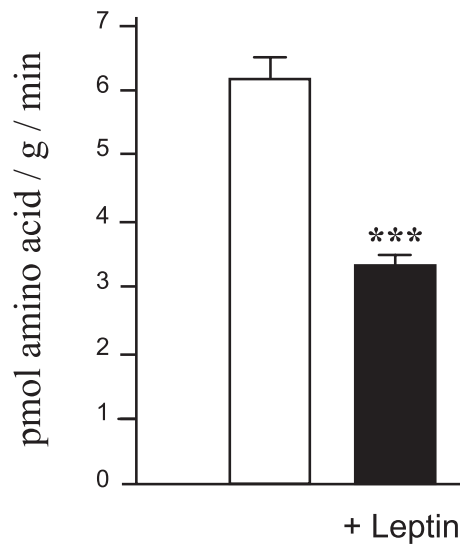

Fig. 1. Effect of leptin on glutamine (Gln) and phenylalanine (Phe) uptake by everted intestinal rings. Uptake of $0.5 \mathrm{mM}$ Gln $(A), 50 \mu \mathrm{M}$ Gln $(B)$, or $0.5 \mathrm{mM}$ Phe $(C)$ was measured in the absence or presence of $0.2 \mathrm{nM}$ leptin after $15-\mathrm{min}$ incubation. Uptake of Gln was also measured in the presence of $25 \mathrm{mM}$ Phe $(A$ and $B)$. Experiments in $A$ and $C$ were performed in the same experimental group. The results are expressed as means $\pm \mathrm{SE}$; $* * * P<0.001$ ( $n=6-18$ from 3 animals).

concentration only ASCT2 was contributing to Gln absorption. The uptake of $0.5 \mathrm{mM}$ Phe, assayed in the same tissue preparation as Fig. $1 A$, was found less than $10 \%$ of $0.5 \mathrm{mM}$ Gln uptake but was also inhibited $(\sim 45 \%)$ by leptin (Fig. $1 C$ ).
Luminal leptin reduces glutamine-induced $I_{s c}$. Leptin effect was further investigated in Ussing chambers, a polarized system that permits the access to either side of the tissue preparation. After the intestinal mucosa was isolated in the chamber and allowed to reach a steady state (usually $40 \mathrm{~min}$ ), tissues were challenged with $10 \mathrm{mM}$ Gln, which induced a rapid (less that $2 \mathrm{~min})$ and significant rise in $I_{\mathrm{sc}}\left(\sim 23 \mu \mathrm{A} / \mathrm{cm}^{2}\right)$. The increase in $I_{\mathrm{sc}}$ was the result of the $\mathrm{Na}^{+}$mucosal-to-serosal movement that sustained the amino acid entry through sodiumdependent amino acid transporter(s). In accordance with the results obtained with intestinal rings (Fig. 1, $A$ and $C$ ), $10 \mathrm{mM}$ Phe induced a small $I_{\mathrm{sc}}$, which was $\sim 12 \%$ of that for Gln (Fig. 2A). Luminal addition of $10 \mathrm{mM}$ Ala also significantly raised $I_{\mathrm{sc}}\left(\Delta I_{\mathrm{sc}} \sim 15 \mu \mathrm{A} / \mathrm{cm}^{2}\right)$, whereas no change in $I_{\mathrm{sc}}$ was observed after $10 \mathrm{mM}$ methyl aminoisobutyric acid (data not shown), indicating the absence of system A participation in the electrogenic uptake of Gln.

Again, in line with the data obtained with intestinal rings (Fig. 1A), $20 \mathrm{mM}$ Phe reduced the Gln-induced $I_{\mathrm{sc}}$ by $\sim 70 \%$ when it was added to the mucosal bath 3 min before $10 \mathrm{mM}$ Gln challenge (Fig. $2 B$ ) and leptin $(10 \mathrm{nM})$ inhibited by $\sim 60 \%$ Gln and Ala-induced $I_{\text {sc }}$ (Fig. $2 C$ ).

Inhibition of $10 \mathrm{mM}$ Gln transport across intestinal mucosa, following rapid incubation with leptin in the mucosal reservoir, was found to be concentration dependent (Fig. 2D). Inhibition was significant with $0.01 \mathrm{nM}(\sim 30 \%)$, maximal for $10 \mathrm{nM}$ $(\sim 80 \%)$, and decreased with $100 \mathrm{nM}$ leptin up to $\sim 50 \%$. The concentration producing a half-maximal inhibition of Gln transport $\left(\mathrm{IC}_{50}\right)$ was $0.1 \mathrm{nM}$ (Fig. $\left.2 D\right)$. Leptin $(10 \mathrm{nM})$ reduced the $I_{\mathrm{sc}}$ induced by $30 \mathrm{mM}$ Gln $(26 \%$ inhibition, $P<0.05)$ and also the small $I_{\mathrm{sc}}$ induced by $1 \mathrm{mM}$ Gln although, in this case, the inhibition did not reach statistical significance (data not shown).

Mucosal vs. serosal leptin. The possible effect of leptin on Gln-induced $I_{\mathrm{sc}}$ acting from the serosal side was also studied in Ussing chambers. As shown in Fig. 2E, $10 \mathrm{nM}$ leptin after 2 min in the serosal bath also decreased the $10 \mathrm{mM}$ Gln-induced $I_{\mathrm{sc}}$ by $\sim 40 \%$. This decrease, however, was smaller than that produced by the hormone acting from the mucosal side, which was around $80 \%$. After $10 \mathrm{~min}$, leptin from the serosal side had no more inhibitory effect while it was still active from the mucosal side (50\% inhibition).

Leptin inhibition of glutamine transport is blocked by leptin receptor antagonist. To examine whether the inhibitory effect of leptin was dependent on leptin receptor, we studied the effect of L39A/D40A, a mutated leptin-based peptide acting as a leptin antagonist (26). As shown in Fig. $2 F$, addition of 50 $\mathrm{nM}$ L39A/D40A to the mucosal bath immediately before 10 $\mathrm{nM}$ leptin reversed leptin inhibition of Gln-induced $I_{\mathrm{sc}}$, whereas $5 \mathrm{nM} \mathrm{L39A/D40A} \mathrm{had} \mathrm{no} \mathrm{effect.}$

Leptin reduces glutamine-induced ASCT2 and $B^{\circ} A T 1$ protein expression. Western blot assays were performed to investigate whether leptin could modify the expression in the plasma membrane of ASCT2 and $\mathrm{B}^{0} \mathrm{AT} 1$ transporters. As shown in Fig. 3, incubation of the intestinal loops with $10 \mathrm{mM}$ Gln during 3 min increased the presence of ASCT2 and, in a lesser extent, of $\mathrm{B}^{0} \mathrm{AT} 1$ in the BBMV (Fig. 3, $A$ and $B$ ). This increase was inhibited when the loops had been previously incubated with 1 $\mathrm{nM}$ leptin for $3 \mathrm{~min}$, showing that leptin reduced Gln-induced ASCT2 and $\mathrm{B}^{0} \mathrm{AT} 1$ expression in the plasma membrane. 
A

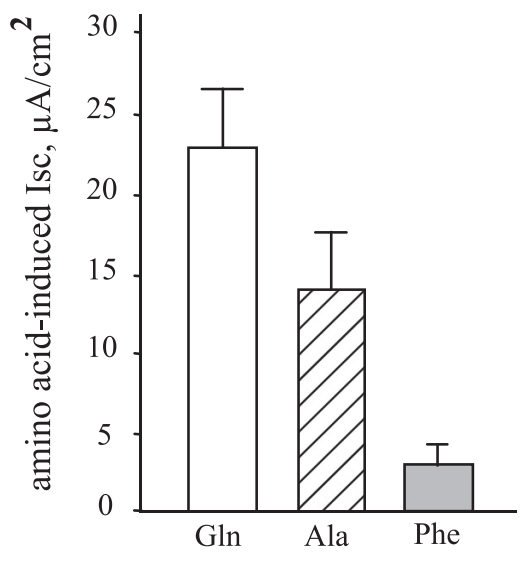

. 2. Leptin inhibition of glutamine induced short-circuit current $\left(I_{\mathrm{sc}}\right)$ in Ussing chamber. $A$ : $I_{\mathrm{sc}}$ induced by $10 \mathrm{mM} \mathrm{Gln}$, alanine (Ala), and Phe $(n=8-29)$. $B$ : effect of $20 \mathrm{mM}$ Phe on $10 \mathrm{mM}$ glutamine-induced $I_{\mathrm{sc}}(n=4)$. $C$ : effect of $10 \mathrm{nM}$ mucosal leptin on $I_{\mathrm{sc}}$ induced by $10 \mathrm{mM}$ Gln or Ala. $D$ : dose response for mucosal leptin inhibition of Glninduced $I_{\text {sc }}$. Leptin was added in the mucosal bath 2 min before tissues were challenged with $10 \mathrm{mM}$ Gln. Values for $I_{\mathrm{sc}}$ were standardized to control value. Each point represents the mean $\pm \mathrm{SE}$ of $4-6$ noncumulative values from 4 separate experiments. E: effect of serosal leptin (sx) vs. mucosal leptin (mq) at $10 \mathrm{nM}$ concentration on $10 \mathrm{mM}$ Gln-induced $I_{\mathrm{sc}}$ (control) $(n=6) .{ }^{*} P<0.05$ vs. control; \#P<0.05 vs. $2 \mathrm{~min} \mathrm{mq}$. $F$ : action of leptin is receptor specific; leptin antagonist L39A/D40A was added to the mucosal bath $5 \mathrm{~min}$ before the addition of leptin, and 3 min later tissues were challenged in the mucosal side with $10 \mathrm{mM}$ Gln $(n=6)$.

\section{C}

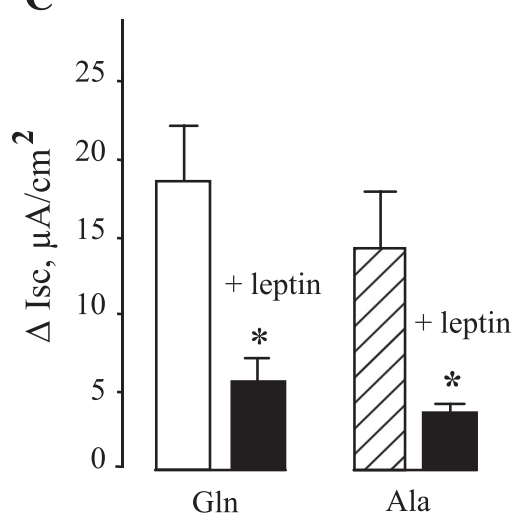

$\mathbf{E}$

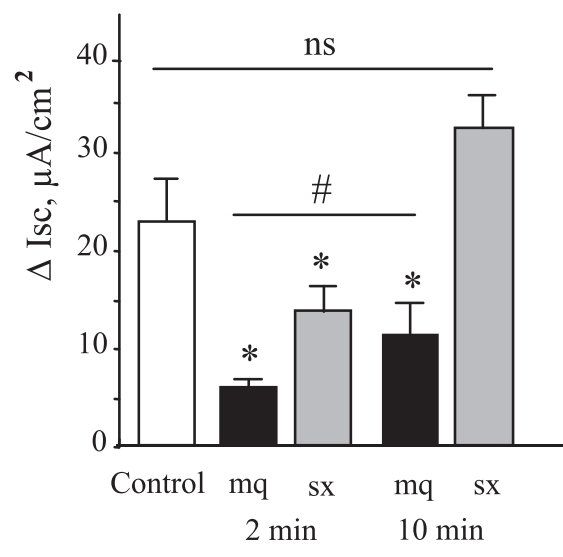

B

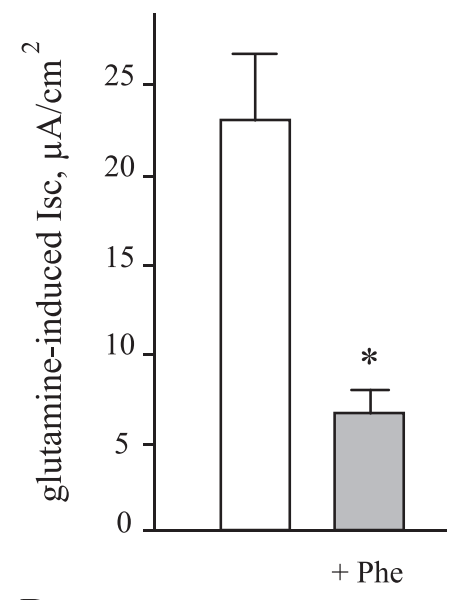

D

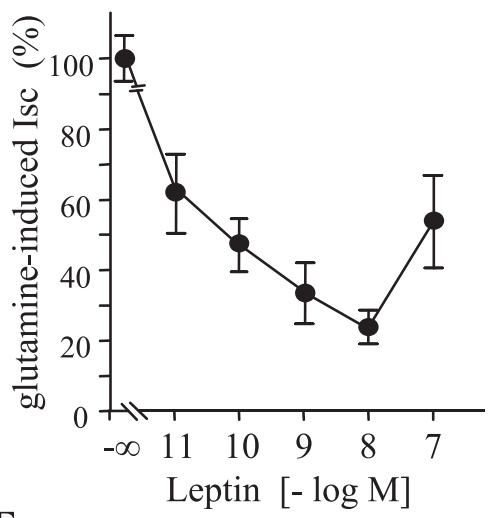

$\mathbf{F}$

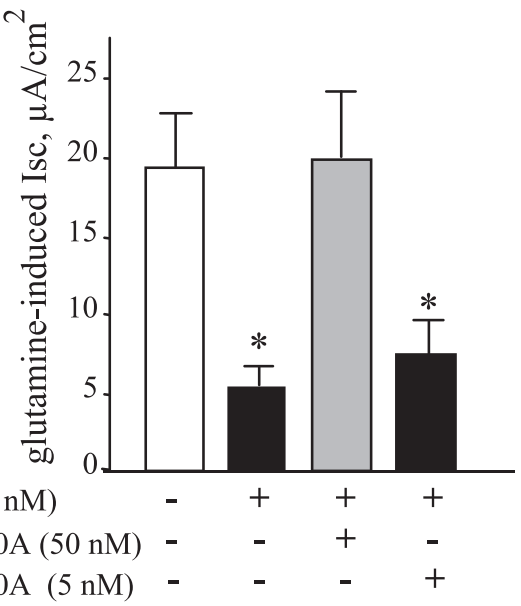

Leptin reduces glutamine-induced ASCT2 and $B^{\circ} A T 1 m R N A$ expression. Finally, the effect of luminal leptin on Glninduced ASCT2 and $\mathrm{B}^{0} \mathrm{AT} 1$ gene expression was studied. Luminal infusion of $10 \mathrm{mM}$ Gln for 60 min markedly increased the level of ASCT2 and $\mathrm{B}^{0} \mathrm{AT} 1 \mathrm{mRNA}$ (6.7-fold and 2.8-fold, respectively compared with their relative controls; Fig. 4, $A$ and $B$ ). When the intestinal loops were first incubated with $1 \mathrm{nM}$ leptin for $3 \mathrm{~min}$ before the Gln infusion, the increase in ASCT2 and $\mathrm{B}^{0} \mathrm{AT} 1 \mathrm{mRNA}$ was significantly reduced $(\sim 55 \%)$. These results indicate that leptin can also regulate Gln-induced ASCT2 and $\mathrm{B}^{0} \mathrm{AT} 1$ mRNA expression.

\section{DISCUSSION}

The present results demonstrate that, in rat intestine, leptin inhibits the absorption of Gln and the protein and mRNA expression of ASCT2 and $\mathrm{B}^{0} \mathrm{AT} 1$, the two major Gln trans- 

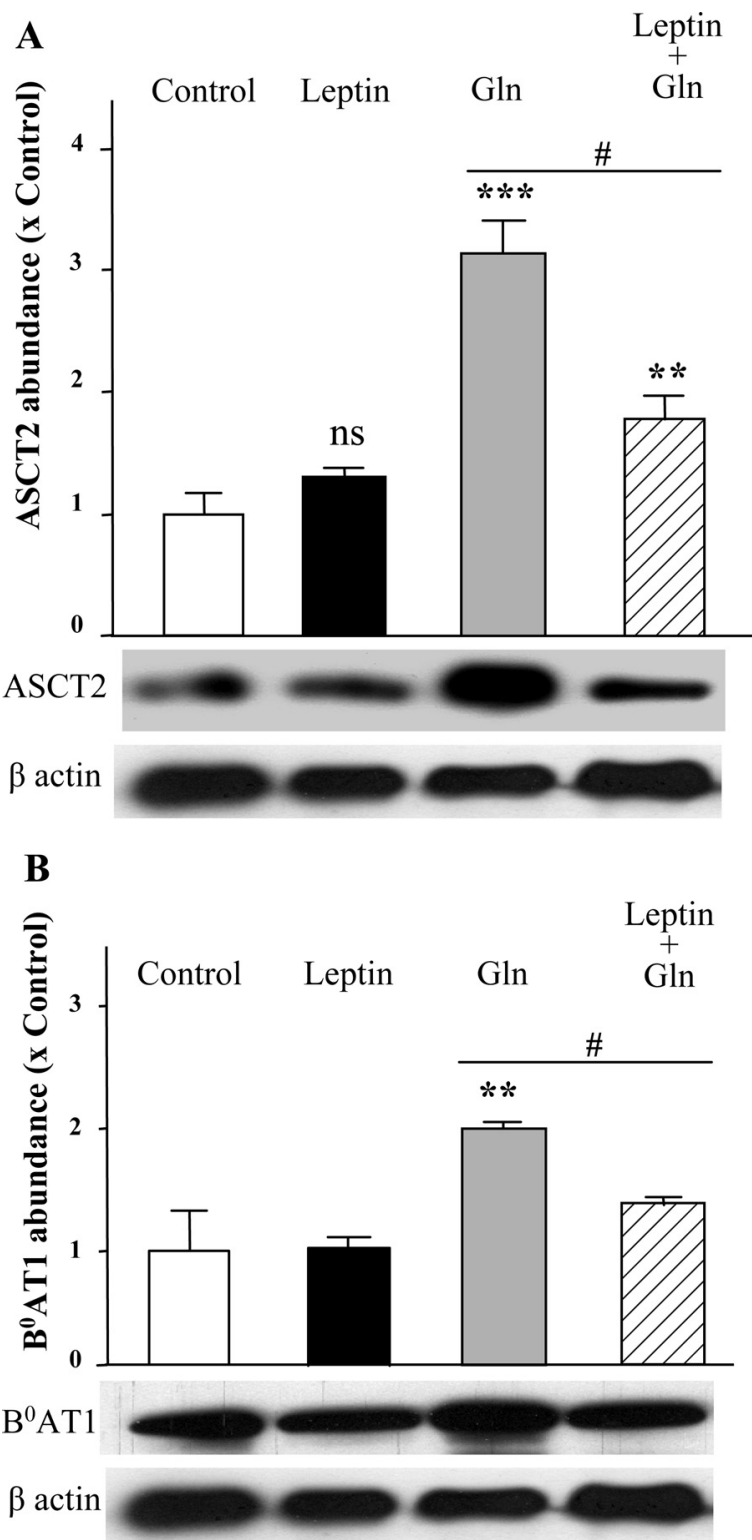

Fig. 3. Effect of luminal leptin on Gln-induced expression of ASCT2 and $\mathrm{B}^{0} \mathrm{AT} 1$ proteins in brush-border membrane $(\mathrm{BBM})$. BBM vesicles were obtained from mucosa of $\mathrm{NaCl}$-treated (control), $1 \mathrm{nM}$ leptin-treated, and 10 $\mathrm{mM}$ Gln-treated (3 min) intestinal loops, and ASCT2 $(A)$ and $\mathrm{B}^{0} \mathrm{AT} 1(B)$ protein expression were analyzed by Western blot. Representative Western blot images are shown. Intensity of the immunoreactive bands was quantified and expressed in relation to control. Results are expressed as means $\pm \mathrm{SE}$ for 3-4 rats per experimental group. $* * P<0.01$ and $* * * P<0.001$ vs. control. $\# P<0.05$ vs. Gln.

porters in the apical membrane of the enterocytes (6), and that this effect is a clear result of the luminal action of the hormone.

Gln, the most abundant amino acid in the body, plays a central role in interorgan nitrogen transfer (13). Circulating Gln concentration is maintained at a relatively constant level, which is critical to avoid Gln depletion in blood and organ dysfunction. The small intestine is the most important organ for the supply of exogenous Gln to the body. Gln is also the major fuel for intestine absorptive cells. Though the transport systems for the entry of L-glutamine by intestinal epithelia cells have been studied in different animal models (6), its regulation by hormones and peptides is not yet completely understood. Growth hormone (GH) and epidermal-growth factor (EGF) can enhance intestinal Gln uptake (27), and a possible hormonal stimulation of ASCT2 in vivo has been suggested (24).

Leptin is now well documented as an important regulator of nutrient transporters from the apical membrane of the enterocytes. Indeed, leptin was shown to control butyrate MCT-1mediated absorption (10) and di-/tripeptide transporter PepT-1 (9) and modulate the activity of glucose and fructose transporters through its action on SGLT1 $(16,19,21)$, GLUT2, and GLUT5 (25). A significant role for leptin in controlling active transport of Gln was previously established in human placental villous fragments where leptin stimulates the activity of system
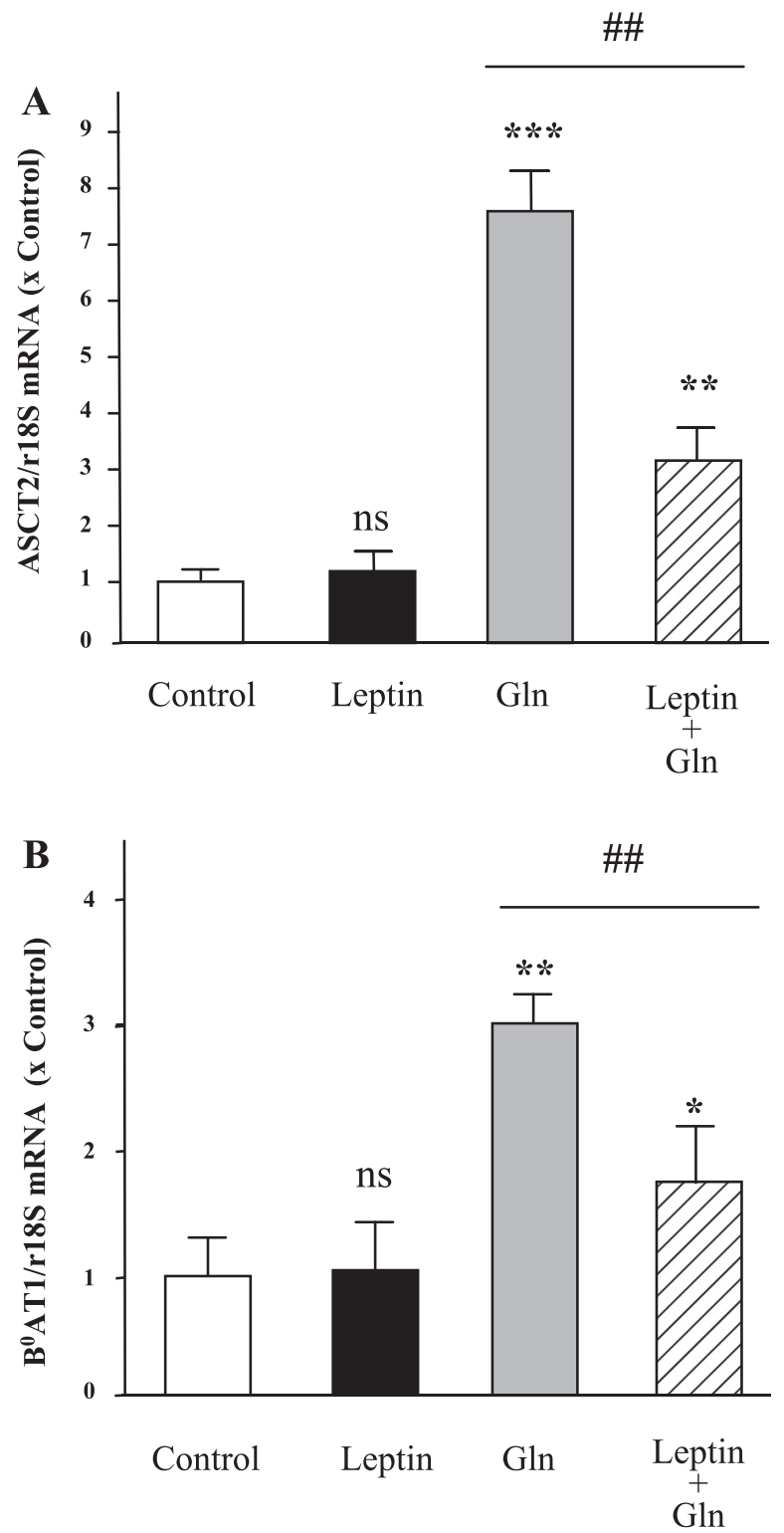

Fig. 4. Effect of leptin on Gln-induced ASCT2 and $\mathrm{B}^{\circ} \mathrm{AT} 1$ gene expression. Total RNA was extracted from mucosa of NaCl-treated (control), $1 \mathrm{nM}$ leptin-treated, and $10 \mathrm{mM}$ Gln-treated $(60 \mathrm{~min})$ intestinal loops, and ASCT2 $(A)$ and $\mathrm{B}^{0} \mathrm{AT} 1(B)$ mRNA expression were analyzed by RT-PCR. Results are expressed as ratio of transporter/r18S mRNA expression in relation to control and presented as means \pm SE of $3-4$ rats per experimental group. $* P<0.05$; $* * P<0.01$, and $* * * P<0.001$ vs. control; $\# P<0.05$ vs. Gln. 
A, thus controlling the availability of this important fuel to placenta cells (20).

Here, the functional studies were first performed in vitro using everted intestinal rings. The same technique was used to demonstrate for the first time that leptin inhibits sugar intestinal transport (21). Even though with this technique the mucosa is exposed to the medium and the access of the hormone to the enterocyte is mostly through the apical membrane, a possible basolateral action of leptin could not be discarded. Therefore, we further measured Gln transport in Ussing chambers, where contribution of mucosal vs. serosal leptin could be distinctly examined and mucosal-to-serosal Gln entry could be followed as sodium-induced $I_{\text {sc }}$. As observed with intestinal rings, leptin pretreatment from the mucosal side induced a rapid and marked reduction of the Gln-induced $I_{\mathrm{sc}}$. This effect was concentration dependent with characteristics of inhibition found in the nanomolar range $(16,21)$. The effect of leptin from the serosal side was found significantly less pronounced and disappeared at the longest incubation time (10 min). These results may reflect the fact that leptin exposed to the serosal side needs to diffuse a few layers of muscle and connective tissues before reaching its receptors on the basolateral membrane of the enterocytes, with possible reduction of the effective concentration. In addition, the membrane surface area for leptin action is smaller when it acts from the serosal side compared with the apical side, and the distance between the receptor and the Gln transporters is higher. After $10 \mathrm{~min}$, the lack of leptin action from the serosal side can be also related to the decrease of its effect from the apical side.

The Ussing chamber technique mimics the relevant action of leptin, which is produced and secreted by gastric cells $(1,11)$ together with its soluble receptor (12) and can flow along the digestive lumen to reach the small intestine and act as a physiological modulator. In fact, using leptin mutein, a leptin receptor antagonist (26), we demonstrate that this modulation requires an effective interaction of leptin with its specific receptor located at the $\mathrm{BBM}$ of the small intestine $(3,9)$. Interestingly, a recent report shows that, in leptin receptordeficient obese Zucker rats, Gln transport is highly increased (29). This is in line with the inhibitory action of leptin as a regulator of the Gln uptake here reported. It is tempting to speculate, therefore, that leptin may act as a brake on the entry of Gln, possibly in balance with another stimulating hormone (i.e., GH or EGF). Interestingly, this leptin-induced action is apparently different from the one recently proposed for angiotensin II that inhibits intestinal glucose uptake but not amino acid transport under normal and diabetic conditions (30, 31).

In the intestine, Gln transport is assumed to be predominantly achieved by the sodium-dependent transporter $\mathrm{B}^{0} \mathrm{AT} 1$ (28). In rat intestinal rings, uptake of Phe, a specific substrate of $\mathrm{B}^{0} \mathrm{AT} 1$, was also inhibited by leptin, indicating that $\mathrm{B}^{0} \mathrm{AT} 1$ was a target for the hormone. Interestingly, Phe uptake was very low compared with Gln uptake at the same concentration, which can be explained by the fact that $\mathrm{B}^{0} \mathrm{AT} 1$ shows lower affinity for its substrates ( $K_{0.5}$ ranging from 1.4 to $4 \mathrm{mM}$ ) compared with ASCT2 $\left(K_{0.5}=\sim 20 \mu \mathrm{M}\right)$ (6). Nevertheless, 25 $\mathrm{mM}$ Phe was able to inhibit by $\sim 65 \%$ Gln uptake, suggesting a higher contribution of $\mathrm{B}^{0} \mathrm{AT} 1$ on Gln absorption in rat intestine under this experimental condition. By employing Ussing chamber, we also found that Phe-induced $I_{\mathrm{sc}}$ was lower compared with the Gln-induced $I_{\mathrm{sc}}$. Aside from $\mathrm{B}^{0} \mathrm{AT} 1$,
ASCT2 is the other sodium-dependent Gln transporter present in the apical membrane of small intestine (6). From the functional studies using $50 \mu \mathrm{M}$ Gln (concentration at which only ASCT2 is responsible for Gln absorption), we also demonstrate that ASCT2 is regulated by leptin.

To assess directly the presence of the two Gln transporters in rat $\mathrm{BBM}$ and responsiveness to luminal substrate and/or leptin, we further used biochemical and molecular approaches. Our results clearly indicate that, in the basal condition, both $\mathrm{B}^{0} \mathrm{AT} 1$ and ASCT2 are present in rat BBM. Their expression in the membrane can be rapidly increased by luminal Gln, and this increase can be reduced by leptin at nanomolar range. Interestingly, the ratio of ASCT2/ $\mathrm{B}^{0} \mathrm{AT} 1$ protein expression in the basal state was low (Fig. 3) and confirmed the reported predominance of $\mathrm{B}^{0} \mathrm{AT} 1$ in intestinal BBM (28). However, after luminal challenge with Gln, more ASCT2 than $\mathrm{B}^{0} \mathrm{AT} 1$ protein was observed to swing into the BBM. These biochemical data would support a major importance of ASCT2 on Gln uptake in rat intestine. However, because of the differences in the experimental conditions, it is not possible to compare the functional and biochemical results to draw conclusions about which transporter is the principal in Gln entrance in the enterocytes. Nevertheless, both functional and biochemical data hallmark the contribution of ASCT2 and $\mathrm{B}^{0} \mathrm{AT} 1$ transporters in Gln uptake.

We further demonstrated that leptin, in addition to its effect on posttranslational regulation, can rapidly trigger transcriptional control of the two Gln transporters. Thus leptin inhibits the Gln-induced increase of ASCT2 and $\mathrm{B}^{0} \mathrm{AT} 1 \mathrm{mRNA}$ levels. Regulation of ASCT2 gene expression by Gln was previously reported in hepatic epithelial cells (7). The stimulation of expression in response to Gln was shown to involve, in part, binding of FXR/RXR to the ASCT2 promoter (8).

In summary, we demonstrate that luminal leptin can modulate the intestinal activity and expression of the Gln transporters ASCT2 and $\mathrm{B}^{0} \mathrm{AT} 1$ in the apical membrane of the enterocytes. Because Gln is known to have both acute and chronic effects on cell metabolism and function (13), the present findings of leptin involvement in the modulation of Gln uptake in both short- and long-term mode of action are believed to be of major importance for the biology of intestinal cells.

\section{ACKNOWLEDGMENTS}

The authors thank Katia Marazova for helpful comments in preparing the manuscript and Asunción Redín for unconditional technical assistance.

\section{GRANTS}

This work was supported by INSERM (France), Ministerio de Ciencia y Tecnología, Spain (Grant BFU2007 60420/BFI), and Fundación Marcelino Botín. The Spanish group is a member of the Network for Cooperative Research on Membrane Transport Proteins (REIT), cofunded by the Ministerio de Educación y Ciencia, Spain, and the European Regional Development Fund (ERDF) (Grant BFU2007-30688-E/BFI). Y. Sakar is a recipient of a fellowship from Fondation pour la Recherche Médicale (FRM) and C. Fanjul from Asociación de Amigos, University of Navarra.

\section{DISCLOSURES}

No conflicts of interest, financial or otherwise, are declared by the authors.

\section{REFERENCES}

1. Bado A, Levasseur S, Attoub S, Kermorgant S, Laigneau JP, Bortoluzzi MN, Moizo L, Lehy T, Guerre-Millo M, Le Marchand-Brustel 
Y. Lewin M. The stomach is a source of leptin. Nature 394: 790-793, 1998.

2. Barrenetxe J, Barber A, Lostao MP. Leptin effect on galactose absorption in mice jejunum. $J$ Physiol Biochem 57: 345-346, 2001.

3. Barrenetxe J, Villaro AC, Guembe L, Pascual I, Muñoz-Navas M, Barber A, Lostao MP. Distribution of the long leptin receptor isoform in brush border, basolateral membrane, and cytoplasm of enterocytes. Gut 50: 797-802, 2002.

4. Barrenetxe J, Sainz N, Barber A, Lostao MP. Involvement of PKC an PKA in the inhibitory effect of leptin on intestinal galactose absorption. Biochem Biophys Res Commun 317: 717-721, 2004.

5. Bode B. Recent molecular advances in mammalian glutamine transport. $J$ Nutr 131: 2475S-2485S, 2001.

6. Broer S. Amino acid transport across mammalian intestinal and renal epithelia. Physiol Rev 88: 249-286, 2008.

7. Bungard CI, McGivan JD. Glutamine availability up-regulates expression of the amino acid transporter protein ASCT2 in HepG2 cells and stimulates the ASCT2 promoter. J Biochem 382: 27-32, 2004.

8. Bungard CI, McGivan JD. Identification of the promoter elements involved in the stimulation of ASCT2 expression by glutamine availability in HepG2 cells and the probable involvement of FXR/RXR dimers. Arch Biochem Biophys 443: 53-59, 2005.

9. Buyse M, Berlioz F, Guilmeau S, Tsocas A, Voisin T, Péranzi G, Merlin D, Laburthe M, Lewin MJM, Rozé C, Bado A. PepT1-mediated epithelial transport of dipeptides and cephalexin is enhanced by luminal leptin in the small intestine. J Clin Invest 108: 1483-1494, 2001.

10. Buyse M, Sitaraman SV, Liu X, Bado A, Merlin D. Luminal leptin enhances CD147/MCT-1-mediated uptake of butyrate in the human intestinal cell line Caco2-BBE. J Biol Chem 277: 28182-28190, 2002.

11. Cammisotto PG, Renaud C, Gingras D, Delvin E, Levy E, Bendayan M. Endocrine and exocrine secretion of leptin by the gastric mucosa. $J$ Histochem Cytochem 53: 851-860, 2005.

12. Cammisotto PG, Gingras D, Renaud C, Levy E, Bendayan M. Secretion of soluble leptin receptors by exocrine and endocrine cells of the gastric mucosa. Am J Physiol Gastrointest Liver Physiol 290: G242-G249, 2006.

13. Curi R, Lagranha CJ, Doi SQ, Sellitti DF, Procopio J, Pithon-Curi TC, Corless M, Newsholme P. Molecular mechanisms of glutamine action. J Cell Physiol 204: 392-401, 2005.

14. De Matteis R, Cinti S. Ultrastructural immunolocalization of leptin receptor in mouse brain. Neuroendocrinology 68: 412-419, 1998.

15. De Matteis R, Puxeddu R, Riva A, Cinti S. Intralobular ducts of human major salivary glands contain leptin and its receptor. J Anat 201: 363-70, 2002.

16. Ducroc R, Guilmeau S, Akasbi K, Devaud H, Buyse M, Bado A. Luminal leptin induces rapid inhibition of active intestinal absorption of glucose mediated by sodium-glucose cotransporter 1. Diabetes 54: $348-$ 354, 2005.

17. Guilmeau S, Buyse M, Bado A. Gastric leptin: a new manager of gastrointestinal function. Curr Opin Pharmacol 4: 1-6, 2004.
18. Iñigo C, Barber A, Lostao MP. Leptin effect on intestinal galactose absorption in ob/ob and $d b / d b$ mice. J Physiol Biochem 60: 93-98, 2004.

19. Iñigo C, Patel N, Kellett GL, Barber A, Lostao MP. Luminal leptin inhibits intestinal sugar absorption in vivo. Acta Physiol (Oxf) 190: 303-310, 2007.

20. Jansson N, Greenwood SL, Johansson BR, Powell TL, Jansson T. Leptin stimulates the activity of the system A amino acid transporter in human placental villous fragments. J Clin Endocrinol Metab 88: 1205 $1211,2003$.

21. Lostao MP, Urdaneta E, Martínez-Ansó E, Barber A, Martínez JA. Presence of leptin receptors in rat small intestinal and leptin effect on sugar absorption. FEBS Lett 42: 302-306, 1998.

22. Margetic S, Gazzola C, Pegg GG, Hill RA. Leptin: a review of its peripheral actions and interactions. Int J Obes Relat Metab Disord 26: 1407-1433, 2002.

23. Martínez-Ansó E, Lostao MP, Martinez JA. Immunohistochemical localization of leptin in rat kidney. Kidney Int 55: 1129-1130, 1999.

24. Palmada M, Speil A, Jeyaraj S, Bohmer C, Lang F. The serine/ threonine kinases SGK1, 3 and PKB stimulate the amino acid transporter ASCT2. Biochem Biophys Res Commun 331: 272-277, 2005.

25. Sakar Y, Nazaret C, Letteron P, Ait Omar A, Avenati M, Viollet B, Ducroc R, Bado A. Positive regulatory control loop between gut leptin and intestinal GLUT2/GLUT5 transporters links to hepatic metabolic functions. PLoS One 4: e7935, 2009.

26. Salomon G, Niv-Spector L, Gussakovsky EE, Gertler A. Large-scale preparation of biologically active mouse and rat leptins and their L39A/ D40A/F41A muteins which act as potent antagonists. Protein Expr Purif 47: 128-136, 2006.

27. Salloum R, Stevens B, Schultz G, Souba W. Regulation of small intestinal glutamine transport by epidermal growth factor. Surgery 113: 552-559, 1993.

28. Talukder JR, Kekuda R, Saha P, Arthur S, Sundaram U. Identification and characterization of rabbit small intestinal villus cell brush border membrane Na-glutamine cotransporter. Am J Physiol Gastrointest Liver Physiol 295: G7-G15, 2008.

29. Wolff BS, Meirelles K, Meng Q, Pan M, Cooney RN. Roux-en-Y gastric bypass (RYGB) alters small intestine glutamine transport in the obese Zucker rat (ZR). Am J Physiol Gastrointest Liver Physiol 297: G594_ G601, 2009.

30. Wong TP, Debnam ES, Leung PS. Involvement of an enterocyte reninangiotensin system in the local control of SGLT1-dependent glucose uptake across the rat small intestinal brush border membrane. $J$ Physiol 584: 613-623, 2007.

31. Wong TP, Debnam ES, Leung PS. Diabetes mellitus and expression of the enterocyte renin-angiotensin system: implications for control of glucose transport across the brush border membrane. Am J Physiol Cell Physiol 297: C601-C610, 2009.

32. Zhang Y, Proenca R, Maffei M, Barone M, Leopold L, Friedman J. Positional cloning of the mouse obese gene and its human homologue. Nature 372: 425-432, 1994. 